\title{
A MULHER NASCE LIVRE E TEM OS MESMOS DIREITOS DO HOMEM ${ }^{1}$
}

\author{
OLIVEN, Leonora Roizen Albek*
}

O trabalho traça um percurso histórico-jurídico e social sobre as relações civis e de trabalho das mulheres durante os séculos XX e XXI a partir dos papeis desempenhados no ambiente familiar e das perspectivas intra e extradomiciliar. As reconfigurações familiares impactam no movimento e na luta pela igualdade em direitos, que acelera a partir do último quadrante do século XX. A pesquisa é bibliográfica e descritiva, amparada em dados estatísticos e fontes documentais e normativas. A análise propõe continuidade na pesquisa, verificando a interação dos processos históricos com a normativa e as demandas sociais.

Palavras-chave: igualdades; mulheres; emancipação; trabalho; historicidade.

\section{WOMAN IS BORN FREE AND REMAINS EQUAL TO MAN IN RIGHTS}

These paper draws a historical-juridical and social trajectory on the civil and labor relations of women during the XX and XXI centuries, based on the roles played in the family environment and the perspectives intra and extra home. Family reconfigurations impact on the movement and the struggle for equality in rights, which accelerates from the last quadrant of the twentieth century. The research is bibliographical and descriptive, supported by statistical data and documentary and normative sources. The analysis proposes continuity in the research, verifying the interaction of the historical processes with the normative and the social demands.

Keywords: equality; women; emancipation; job; historicity.

\footnotetext{
*Doutora em Direito do Programa de Pós-Graduação em Direito da Universidade Veiga de Almeida, mestre me Psicanálise, Saúde e Sociedade pela Universidade Veiga de Almeida. Docente colaboradora do PPGD-UVA, docente de graduação UVA e IBMEC, Rio de janeiro. Endereço de email: leonora.oliven@gmail.com e endereço para acessar o lattes http://lattes.cnpq.br/1070351326253691

${ }^{1}$ Art. $1^{\circ}$ da Declaração dos Direitos da Mulher e da Cidadã.
} 


\section{Introdução}

O trabalho proposto é desenvolvido a partir de pesquisas que envolvem a historicidade do direito e das famílias, agora com recorte e análise histórico-jurídica de direitos das mulheres nas relações de trabalho intra e extrafamiliar. As dificuldades e resistências encontradas nesse percurso ensejam a comparação entre institutos jurídicos, de papeis domésticos e do exercício das funções familiares e encontram em registros institucionais sobre o trabalho da mulher vetores de informação e de análise da divisão sexual nas relações de trabalhos. Eles podem servir de suporte para o conhecimento de movimentos sociais, com a identificação dos avanços e dos retrocessos nas relações familiares e oferecer reflexões para novas políticas.

A metodologia descritiva, com a pesquisa bibliográfica a os assentamentos em documentos históricos, buscará identificar e estabelecer relações entre a sociedade os fenômenos jurídicos. Os dados referentes ao trabalho da mulher, advindos de pesquisas mais recentes referenciadas à área, considerando o aumento na produção e na medição de metadados, apoiam a análise. Nesse percurso, as fontes normativas e históricas são sopesadas para retratar o momento histórico aonde foram propostas, rejeitadas ou aprovadas.

Acredita-se que as ideias e atores sociais integram e apoiam o diálogo entre a história, a sociedade e o direito. Através dos fios condutores desempenhados pelas legislações civis e trabalhistas, apresenta as construções legais de forma concomitante aos influxos sociais.

As mulheres desde sempre trabalharam e não apenas no ambiente doméstico, sem que a valoração das atividades fosse adequada ou respeitada, ensejando propostas por programas normativos de igualdade jurídica e salarial. Elas são históricas e contém reivindicações e exigências necessárias à realização de conceitos como justiça e equidade, o que justifica a investigação, pois ainda assim as diferenças parecem cristalizadas.

Tendo por objetivo revelar parte das lutas sociais e políticas pela igualdade em direitos civis, nas relações familiares e conjugais e nas de trabalho da mulher, a pesquisa 


\section{MÍDIA, (IN)FORMAÇÃO E DECISÕES JUDICIAIS: UMA COMPREENSÃO DA \\ HERMENÊUTICA NA SOCIEDADE ATUAL.}

transita entre os arranjos dos séculos XX e XXI. Encara as suas construções para identificar nas conquistas e recomposições as repercussões no plano jurídico que poderão alcançar em determinados momentos mais ou menos oportunidades para a realização das igualdades.

O percurso historiográfico permitirá conhecer esses pontos para posteriormente analisar o cenário contemporâneo e identificar o comportamento legal em face da mulher na pluralidade de papeis desempenhados e como eles repercutem na mulher contemporânea em exercício de atividade profissional.

2. A mulher e a legislação civil no Brasil do século XX

A normativa civil brasileira que inicia o século $\mathrm{XX}^{2}$ estava estruturada na cultura patriarcal. Os bens com conteúdo econômico deveriam ser garantidos e para tanto era imprescindível a filiação legítima, essa compreendida como a advinda do casamento A proteção da família casta, legitimada pelo casamento monogâmico, exige que as mulheres permaneçam em uma posição subalterna e respondendo aos desejos e demandas do homem, seu pai e marido.

Desde a Colônia esse era o modelo vigente, com o casamento religioso focado na manutenção desses valores. O casamento da razão estimulava os ajustes para a composição das novas famílias e a endogamia mitigada seria uma solução para tornar possível resguardar esse ativo patrimonial dentro dos mesmos clãs, estimulando o casamento intrafamiliares. Aos casar parentes entre si, a teia de proteção dentro do mesmo grupo consanguíneo e doméstico seria a forma de garantir e de aumentar os bens.

As mulheres integravam de forma ativa, ainda que não necessariamente de livre vontade, o sistema de trocas necessário à manutenção desses acordos e alianças entre os grupos (LÉVI-STRAUSS, 1956). O aparelhamento de sustentação é composto por diferentes laços e relações sociais, sendo o casamento de interesse de todo o grupo e não apenas dos noivos. Ele é circular e retroalimenta a formação de famílias nucleares, que são ligadas às famílias extensas por laços preferencialmente de consanguinidade, sendo comum que duas irmãs se casassem com dois irmãos (OLIVEIRA, 2005, p.171-172),

\footnotetext{
${ }^{2}$ Código Civil, Lei n ${ }^{\circ}$ 3.071/ 1916.
} 
fortalecendo as alianças. Também a afinidade e o compadrio integravam esse sistema, organizando as famílias, a política e as relações de trabalho.

A luta liderada no século XVIII na Inglaterra por Mary Wollstonecraft pela educação de mulheres deu novo corpo ao processo de emancipação. No Brasil, Nísia Floresta Brasileira publicou em 1832 a tradução livre do livro $A$ vindication of the rights of woman, de Mary Wollstonecraft, adaptando à realidade brasileira e a chamou de Direito das mulheres e injustiça dos homens (Araújo, 2011). Os contextos são distintos em épocas, histórias e culturas, que se encontram na ideia da educação como instrumento de rompimento com as desigualdades de gêneros.

A atribuição e mais direitos aos homens do que às mulheres, e a manutenção dessa posição de vantagem, se estruturava em uma naturalização sem suporte forte o suficiente a justificar a diferença, o que inexiste. Afirma Hunt que no ambiente de consolidação dos Direitos Humanos, propostos como "universais, iguais e naturais, era preciso explicar por quê. Em consequência, o século XIX presenciou uma explosão de explicações biológicas da diferença” (HUNT, 2009, p. 125), disseminando práticas como o sexismo, racismo e antissemitismo.

Para além da igualdade formal e da aplicação de direitos a todas as pessoas, havia a necessidade de implementação da igualdade material. Com medidas de discriminação positiva e de acesso à educação, cultura, voto e trabalho, seriam possíveis lutas pela igualdade de direitos. Até então, o que havia era a redução de direitos de um determinado grupo (mulheres) e a atribuição de mais direitos a outro grupo (homens), inviabilizando o exercício da cidadania e dos direitos civis.

A legislação brasileira, em específico o Código Civil de 1916, foi estruturado em modelo iluminista racionalista e tem na família, na propriedade e nos contratos os seus valores, indicando os vetores de atuação e de interesse daquela sociedade. Ele não integra a mulher nesse processo, que terá posição secundária em aspectos legais e sociais.

A legislação naturaliza o protagonismo dos homens e a inferioridade das mulheres, especialmente as casadas. A regularização das relações sexuais entre os casais é realizada através do casamento civil entre um homem e uma mulher, e indissolúvel pela manifestação da vontade. Da mesma forma o matrimonio atinge as relações patrimoniais e os direitos filiais, na medida em que o estatuto filial só seria exercitado 


\section{MÍDIA, (IN)FORMAÇÃO E DECISÕES JUDICIAIS: UMA COMPREENSÃO DA \\ HERMENÊUTICA NA SOCIEDADE ATUAL.}

pelos filhos legítimos, ou seja, aqueles nascidos na constância da sociedade conjugal. Era necessário o casamento para a regularização da filiação, com a intervenção legal do marido na educação e criação dos filhos, ainda que de fato essa fosse desempenhada pela mãe.

Se de um lado a mulher era incentivada ao casamento, investindo em aprendizados típicos das atividades domésticas, como cozer e coser, o mesmo casamento retirava direitos das mulheres. Para além de qualquer opressão existente, ele reduzia a capacidade civil, impedindo a autonomia na tomada de decisões sobre o trabalho extraconjugal, em especial no caso das mulheres brancas e de classe média, e a escolha do domicilio familiar. A necessidade da outorga conjugal para determinados atos referentes à disposição patrimonial e de atividades laborais criava a possibilidade de o marido exigir o cumprimento de determinadas obrigações em contrapartida, o que violava os direitos humanos das mulheres.

Não casar nem sempre era uma opção e as famílias esperavam que as filhas se casassem estabelecendo as novas alianças, como se esse fosse um dever, também desonerando o pai da continuidade pela manutenção de seu sustento. No entanto, nem sempre as mulheres estavam profissionalmente preparadas para o trabalho externo em igualdade de condições com os homens, submetendo-se, ao transgredir, a salários inferiores e às mais diversas formas de violência e de abusos nas relações laborais.

O Brasil recusava a a igualdade jurídica entre homens e mulheres, bem como nas relações conjugais. As orientações sobre a igualdade sugeridas em 1945 na IX Conferência Interamericana das Nações Unidas, em Bogotá, ainda que convertidas em lei em 1950, não eram aplicadas ou reconhecidas pelos congressistas brasileiros para alterar as normas infraconstitucionais. Conservadores, evitavam o sentido de igualdade fática ou jurídica. Permanecer com o controle e poder sobre a vida de suas mulheres e filhos era valor a ser mantido. A mulher, especialmente a casada, deveria se submeter ao marido sob a falsa premissa da proteção.

Se de um lado era necessária a regulamentação do trabalho em si, de outro lado era forçoso o reconhecimento da igualdade jurídica entre os gêneros e entre os casais. A diferença nas relações jurídicas distanciava a mulher da autonomia pretendida.

3. O dirigismo marital para a vida e o trabalho da mulher.

Rev. Brasileira de História do Direito | e-ISSN: 2526-009X| Goiânia| v. 5 | n. 1 | p. 1 - 20 | Jan/Jun. 2019 
Na luta pela emancipação, um dos vértices se dirige ao trabalho extramuros e são diversas as demandas a serem enfrentadas. Ainda que não houvesse impedimento legal ao trabalho das mulheres, ele só poderia ser exercitado pelas casadas se houvesse a autorização do marido, o que nem sempre era possível, muitos resistiam. Havia ainda a dificuldade de um mercado de trabalho paritário, que oferecesse igualdade de condições ao desenvolvimento da atividade fim, e os salários, ainda ${ }^{3}$ inferiores aos dos homens.

Se solteiras, para que as mulheres com menos de vinte e um anos, idade para o pleno exercício da capacidade civil no Código Civil de 1916, pudessem trabalhar, era necessária a autorização paterna, considerando o pátrio poder. Somem-se ainda as dificuldades de acesso aos estudos especializados e às experiências profissionais, enraizando a dependência econômica, possivelmente servindo à estrutura de poder masculino e de dominação.

As exigências legais dificultavam as contratações como se fossem alerta para que as mulheres não esquecessem que o casamento impunha deveres e atenção com a casa, o marido e os filhos, e que deveriam antes de tudo se desincumbir dessas obrigações. A paz familiar seria garantida pela sua presença no ambiente doméstico, sendo a responsável por bem gerenciar e desincumbir essas atividades. Dentre os acordos firmados pelas famílias, as atenções domésticas (mulheres)-sustento familiares (homens) eram feitos em nome das filhas. O binômio suportava posição de vantagem jurídica e social aos homens e inibia o desenvolvimento educacional e profissional das mulheres, garantindo a dependência. Sem amplo acesso ao ensino, as atividades remuneradas eram restritas àquelas que remetiam ao trabalho doméstico, como os cuidados com crianças e de costuras. Poucas mulheres tinham acesso aos cursos superiores ou técnicos que permitissem o efetivo crescimento profissional. Tarefeiras, cumprindo extradomicílio com atividades semelhantes às do lar, o trabalho seria tipicamente doméstico, geralmente era atribuído às mulheres negras e às mais pobres como empregadas, como ainda se apresenta ${ }^{4}$.

\footnotetext{
${ }^{3}$ Estudo especial feito pelo IBGE para o Dia Internacional da Mulher, 2018, com base na Pesquisa Nacional por Amostra de Domicílios Contínua (PNAD Contínua), demonstrou que 2018 a diferença salarial entre homens e mulheres é mensurada em 20,5\% menor para as mulheres disponível em https://agenciadenoticias.ibge.gov.br

${ }^{4}$ Estudo Retrato das Desigualdades de Gênero e Raça com base em séries históricas de 1995 a 2015 da Pesquisa Nacional por Amostra de Domicílios (Pnad), do IBGE, 2017. Disponível em http://www.ipea.gov.br/portal/images/stories/PDFs/170306_retrato_das_desigualdades_de_genero_raca.p df Acesso 03 abr. 2019.
} 


\section{MÍDIA, (IN)FORMAÇÃO E DECISÕES JUDICIAIS: UMA COMPREENSÃO DA HERMENÊUTICA NA SOCIEDADE ATUAL.}

O discurso tendencioso apontava riscos à honra das mulheres com o trabalho fora do lar. Ele considerava os arroubos masculinos em passar dias inteiros com mulheres em ambientes fechados, como lojas e escritórios, e a incapacidade da mulher em saber como se portar ou em se defender, talvez até sucumbindo aos desejos deles. A ordem era: as mulheres deveriam ser tuteladas, impedindo a degradação das famílias, fossem elas casadas ou solteiras, preservando as aparências e a honra familiar, atreladas ao recato doméstico.

A imprescindibilidade de autorização marital ao trabalho da mulher evidencia "que o argumento da moral, em verdade, é o argumento da conservação da hierarquia entre homens e mulheres" (LOPES, 2006, p. 417). Se a mulher trabalhasse livremente, não mais viveria tão subjugada e dependente do marido. Os homens desejavam e precisavam manter a dependência, e ela tinha como freio a autorização, para o exercício de sua força e do poder econômico e social, reforçando os espaços até então ocupados.

O Brasil resistia à autonomia das mulheres, o que implicaria em mudanças relacionais não desejadas pela família conservadora. A exigência da autorização era amparada o vácuo legislativo sobre os direitos das trabalhadoras, que encontravam especial preferência na contratação pela indústria têxtil a) pela mão-de-obra hábil para essas atividades e mais barata; b) por mais concentradas; c) por não serem as responsáveis pela economia doméstica; d) por não terem aspirações profissionais relevantes, se submetendo mais facilmente às orientações (LOPES, 2006). A premissa de fragilidade física e biológica (GOMES, 1976, p.469) era também justificativa para a limitação ao trabalho extradomiciliar da mulher.

$\mathrm{Na}$ ordem internacional, havia orientação da $\mathrm{OIT}^{5}$ para que efetivamente se implementasse a igualdade de condições de trabalho e de salários para homens e mulheres. A igualdade pressupõe o livre poder de escolha e de decisão da mulher para a seleção de suas atividades sem qualquer intervenção de terceiros.

O Ministério do Trabalho, Indústria e Comércio, criado em 1931 por Getúlio Vargas, indica a igualdade jurídica a todos os trabalhadores urbanos, como férias e fixação de jornada de trabalho. Institui garantias às gestantes e creches para os filhos pequenos, mas não liberta as mulheres do jugo marital, mantendo a exigência de

\footnotetext{
${ }^{5}$ Constituição da OIT, 1919. Disponível em http://www.oitbrasil.org.br/content/importancia-daigualdade-de-genero-no-mundo-do-trabalho
} 
autorização conjugal ao trabalho. $\mathrm{O}$ autorizativo mitiga a autonomia, demonstrando não haver igualdade.

Em 1943, a legislação trabalhista (CLT) cria dificuldades ao trabalho noturno para as mulheres. Com restrições de horários para que as mulheres estivessem em casa para mais uma jornada quando do retorno do marido ao lar conjugal, dificulta as atividades externas e demonstra a preferência pelo trabalho intrafamiliar da mulher. A casa seria o ambiente natural de trânsito feminino e a família deveria estar em posição superior aos demais interesses. O mito da supermãe, possivelmente decorrente do costume colonial de que a mulher deveria zelar pelos cuidados, saúde e organização do patrimônio doméstico (COSTA, 1979, p.103), permanece no imaginário social. O foco da realização externa pessoal e do grupo familiar está centrado no homem e nas oportunidades a ele oferecidas. O protagonismo social é masculino e as liberdades não encontram o seu significado semântico ou jurídico.

O país legal diferia do real. Esse ampliava a busca das mulheres por mais e melhores postos de trabalho, bem como por equidade salarial, enquanto aquele exigia a autorização marital e limitava os horários e funções. Romper com esses paradigmas demandou tempo, investimento e divulgação para possibilitar o compartilhamento das ideias feministas para enfrentar a questão da alteração normativa. A profissionalização seria capaz de promover a independência financeira e o direito ao voto ampliaria o alcance da autonomia.

A Federação Brasileira pelo Progresso Feminino, organizado por Bertha Lutz, promovia debates enfrentando as diferenças entre os direitos e os deveres de homens e mulheres na convivência familiar ${ }^{6}$. Propunham a mudança normativa a) através do voto; b) da eleição e mulheres ao Poder Legislativo. A percepção de que as leis feitas por homens protegem os interesses dos homens não era nova e da militância advém o primeiro Código Eleitoral Brasileiro?

A lei atenderá parcialmente às demandas das mulheres. Para ser eleitor era necessário ser civilmente capaz, mas as mulheres casadas necessitavam da permissão do marido para o voto e a outorga consolida o costume da submissão. Esse acordo possivelmente atrelaria o voto da mulher ao de seu marido, caso desejasse satisfazer o seu direito. As mulheres solteiras e viúvas deveriam comprovar economia própria para

\footnotetext{
${ }^{6} \mathrm{http}: / /$ www.portalsaofrancisco.com.br/alfa/feminismo/feminismo.php

${ }^{7}$ Decreto n ${ }^{\circ} 21.076$, de 24 de fevereiro de 1932.
} 


\section{MÍDIA, (IN)FORMAÇÃO E DECISÕES JUDICIAIS: UMA COMPREENSÃO DA \\ HERMENÊUTICA NA SOCIEDADE ATUAL.}

que pudessem votar, revelando como o patrimônio se sobrepunha aos direitos da personalidade, retrato típico do liberalismo do período. O voto da mulher é então facultativo e condicionado, revelando a insignificância de sua atuação política.

Ainda assim, e para atrair mais pessoas aos debates, inclusive dos homens ao movimento emancipatório, "as feministas do Brasil argumentaram e convenceram homens e mulheres que a educação feminina só traria benefícios à sociedade" (GARCIA, 2018). Ampliar o acesso das mulheres à educação técnica e formal permitiria reduzir a dominação de gênero nos ambientes educacionais, políticos e econômicos.

São então apresentados projetos de $l \mathrm{ei}^{8}$ propondo modificações no Código Civil para as normativas de direito das famílias, em especial no que tange à submissão legal das mulheres e às desigualdades, formas de reduzir a discriminação em face das mulheres. Entre a publicação do Código Civil e da lei que busca alguma igualdade entre homens e mulheres, foram quarenta e seis anos. A luta começava.

A Lei $n^{\circ} 4.121 / 1962$ ficou conhecida como Estatuto da Mulher Casada. Ela alterava o ordenamento civil para devolver às mulheres algo que havia sido retirado e que era imprescindível: a sua capacidade civil íntegra e plena. A mulher casada saía de um estado de menoridade imposta pelo desejo do homem em dirigir as vidas de suas mulheres. Se assenhoram das identidades, ideias e ideais para exigir que as decisões sobre as próprias vidas sejam e livre escolha.

O diploma atribui determinados direitos que visam uma igualdade restrita, não integral, implicando em um avanço cada vez maior no processo emancipatório e que não mais terá retorno. Ainda assim, a nova lei é garantidora de direitos do homem, pois se flexibiliza a autonomia em determinados setores, mantém a desigualdade decisória, permanecendo o marido como o chefe da sociedade conjugal.

A retomada da capacidade civil liberta a mulher da decisão ou interferência do marido no exercício de atividades laborativas. A partir do momento em que é possível o trabalho remunerado sem requisitos autorizativos, a mulher também se torna responsável pela contribuição financeira na economia doméstica. Os valores percebidos com a atividade remunerada pertencem exclusivamente às mulheres, assim como os bens adquiridos com eles, consistindo bens particulares ou privados. Esse instituto de

\footnotetext{
${ }^{8}$ Mozart Lago em 1952, projeto escrito pelas advogadas por Romy Martins Medeiros da Fonseca e Orminda Ribeiro Bastos; não foi aprovado. Nelson Carneiro também militava para as alterações.
} 
bens reservados é instituído para permitir a administração patrimonial autônoma por suas donas sem a ingerência marital, valorizando a independência.

A emancipação avança através da capacitação profissional em cursos universitários $^{9}$ e profissionalizantes, que passam a receber mais mulheres interessadas em capacitação técnica e profissional. As dificuldades para os estudos, considerados como "segunda jornada de trabalho e do significado da maternidade" (CASTRO e YAMAMOTO, 1988) percebidas nos cursos de psicologia, se estendem por outras áreas de conhecimento, com mais homens habilitados às profissões extramuros.

A redução das diferenças de características produtivas amplia a ocupação do espaço público pelas mulheres. Se antes o ambiente doméstico era o possível e de esperada realização, o fortalecimento da autoestima e das relações interpessoais criadas para além da atmosfera familiar revigora a luta pelo divórcio ${ }^{10}$ no Brasil. A possibilidade de dissolução do vínculo conjugal pela manifestação da vontade renovará as reconfigurações. Haverá maior participação das mulheres na política, pressionando pelo autorizativo liberatório, e no mercado de trabalho, revelando famílias autossustentáveis. As transformações nos paradigmas e no modelo familiar mononuclear para plurais ampliam essa participação no trabalho formal. Esse processo altera a vida doméstica como até então consolidada.

Se a industrialização foi marco ao transferir o trabalho das casas para as fábricas, a reorganização do espaço familiar, com o aumento do trabalho externo, evidencia modificações na atitude da mulher. A emancipação afeta o efetivo exercício da cidadania e explica a constante vigília para evitar as desigualdades sociais e jurídicas consolidadas no modelo brasileiro.

\section{As novas famílias}

Os anos 1980 foram férteis em reconfigurações familiares. Assumir que há famílias compostas por apenas um dos genitores e os seus filhos revoluciona a ideia tradicional de família nuclear triangular pai-mãe-filhos. As famílias monoparentais saem da obscuridade para receber proteção legislativa e abrem espaço para debates para

\footnotetext{
${ }^{9}$ Os cursos de psicologia, com marco legal em 1963, recebem majoritariamente mulheres interessadas na então nova ciência, regulamentada no Brasil como profissão em 1962, Lei nº 4.119.

${ }^{10}$ Emenda Constitucional no 9/1977 e Lei no $6515 / 1977$.
} 
a liberdade sexual, o trabalho da mulher e a responsabilidade individual. Nelas não há par parental a contribuir para o sustento e a educação dos filhos. O único genitor/genitora é o compromissado pelo aporte financeiro e pelo exercício de todos os aspectos decorrentes da autoridade parental. A modalidade parece fortalecer a compreensão sobre o trabalho externo da mulher, especialmente quando é a única responsável pela casa. A necessidade econômica parece uma causa satisfatória a permitir maior liberdade de ação.

A Lei do Divórcio, de 1977, ao autorizar a dissolução de matrimônios, também abre espaço para o trabalho da mulher. Divorciada, adquire autonomia sobre a sua história e assume obrigações financeiras, forçando a sua entrada e permanência no mercado de trabalho.

A lei viabiliza a formação de outras famílias. Os divorciados, se o desejarem, podem contrair novas núpcias. O Brasil de 1984 teve 31.85 processos de divórcio encerrados e 936.070 casamentos $^{11}$. Desses matrimônios, 868.978 foram realizados entre casais solteiros. Os divorciados remaridavam: 7429 mulheres divorciadas se casaram com homens solteiros, 1199 com homens viúvos e 1961 com homens divorciados, demonstrando o crédito no casamento civil. Não há registros em coletas de dados sobre as uniões informais para o período, ainda que elas sempre existissem.

O reconhecimento das famílias informais, não cartorizadas, provoca discussões com repercussões jurídicas. A reflexão histórica interpreta os símbolos sociais e atua suscitando dúvidas, questionando as regras, reivindicando o protagonismo das pluralidades familiares. São feitas exigências em nome da legalização de composições afetivas como famílias, demandando o desempenho do direito em movimentos mais ou menos rápidos, controversos e por vezes diversos do tempo da sociedade.

A união estável, assim reconhecida na Constituição Federal de 1988, demandou a edição de duas leis. A lei no 8971/1994 inovou ao atribuir direitos sucessórios aos companheiros em igualdade de condições aos do casamento, e ainda inseriu a possibilidade de usufruto vidual aos conviventes caso não herdassem em propriedade. Também reconhece a possibilidade de distribuição patrimonial inter vivos ou mortis causa na aquisição de patrimônio durante a união, exigindo a demonstração de esforço

\footnotetext{
${ }^{11}$ IBGE, Séries Históricas, Estatísticas do Registro Civil em pesquisa de 1984, primeiro ano em que os dados sobre divórcios foram incorporados às pesquisas. Disponível em https://biblioteca.ibge.gov.br/visualizacao/periodicos/135/rc_1984_v11.pdf Acesso 04 abr. 2019.
} 
comum contributivo, o que afastou muitas mulheres das partilhas de bens, pois nem todas exerciam atividades remuneradas, mesmo contribuindo com o seu trabalho nas atividades familiares, não reconhecido e sequer prestigiado.

A Lei $n^{\circ}$ 9278/1996 busca corrigir o equívoco e atribui aos conviventes a possibilidade de escolha de regime de bens, garantindo a contribuição presumida, e o direito real de habitação. $\mathrm{O}$ instituto reconhece a necessidade em proteger a moradia do sobrevivo e coloca cônjuges e companheiros em posições idênticas na cadeia sucessória.

O Código Civil de 2002 retrocederá e indicará direitos sucessórios aos companheiros em condições inferiores àqueles já reconhecidos. $\mathrm{O}$ debate obteve resposta tão somente em 2017, quando o Supremo Tribunal Federal (STF) decidiu ${ }^{12}$ pela inexistência de hierarquia entre as famílias e determinou a aplicação do mesmo dispositivo nas situações-problema. A família tradicional monogâmica e inicialmente formada pelo casamento dificultava a igualdade jurídica entre cônjuges e companheiros. O longo lapso temporal demonstra resistências às mudanças jurídicas, todas elas advindas de ativismo judicial.

As famílias ensambladas ou mosaicas, tentaculares, são compostas por grupos plurais de pais e filhos. Elas se estruturam em grupos polinucleares, demonstrando outro modelo. Aqui há para debates relevantes para as novas relações de trabalho, pois essa família agrega filhos conjuntos e unilaterais, com diferentes unidades do que até então conhecido. A recomposição ou criação de outra estrutura familiar recepciona outros personagens, todos protagonistas de suas vidas.

Ela parece ser mais elástica e colaborativa exatamente por integrada por vários conjuntos familiares anteriores, agora reunificados em um. O modelo apresenta novos desafios ao sustento de filhos comuns ou híbridos, reunidos pelos afetos dos pais em novos núcleos, e parece ampliar a corresponsabilidade na educação e sustento do lar, implicando homens e mulheres em papeis dúplices de cuidadores e provedores. Os sinais diacríticos possivelmente vão se dissolvendo, ou esmaecendo as suas cores, nas famílias reconfiguradas.

\footnotetext{
${ }^{12}$ Tema 809 da repercussão geral, por maioria e nos termos do voto do Ministro Relator, deu provimento ao recurso, para reconhecer de forma incidental a inconstitucionalidade do art. 1.790 do CC/2002 e declarar o direito da recorrente a participar da herança de seu companheiro em conformidade com o regime jurídico estabelecido no art. 1.829 do Código Civil de 2002. Disponível em http://portal.stf.jus.br Acesso em 17 out. 2018.
} 


\section{MÍDIA, (IN)FORMAÇÃO E DECISÕES JUDICIAIS: UMA COMPREENSÃO DA \\ HERMENÊUTICA NA SOCIEDADE ATUAL.}

Surgem então outras questões que são contemporâneas ao novo lugar que toda a família precisará ocupar. A mãe que agora está fora de casa e busca melhores colocações e realizações profissionais e condições de trabalho e salariais paritários, pode ser uma mãe que por vezes se sente culpada pela rapidez com que precisa retornar ao trabalho ou pelo excesso de horas dedicadas ás atividades profissionais. Esses fatos podem permitir ao homem descobrir outro papel na dinâmica familiar, diferente daquele tradicional. Poderá tornar-se mais continente e responsável não apenas pelo sustento e educação, assumindo outros encargos antes naturalizados como tipicamente femininos. Os filhos também se redesenharão. A família contemporânea exige maior autonomia filial, preparando-as para as responsabilidades pessoais e sociais. Os novos papéis familiares e o desempenho das funções parentais estão sendo reescritas.

Apenas em $2011^{13}$ foi possível o reconhecimento das relações familiares caracterizadas como uniões estáveis entre casais homoafetivos e ele adveio da interpretação do Supremo Tribunal Federal. A Resolução n. 175, de 14.05.2013, do Conselho Nacional de Justiça - CNJ, organizou a habilitação e a celebração de casamento civil ou de conversão de união estável em casamento entre pessoas de mesmo sexo, proibindo a recusa do registro civil em celebrá-los.

As violações e as respostas agressivas eram contundentes - e ainda são tornando o movimento lento e marginalizando os homossexuais, impedindo as liberdades identitárias e amorosas. Para Hunt, os direitos humanos dependem de um juízo de valor advindo das emoções e da razão e decorre de "apelo emocional: ela é convincente se ressoa dentro de cada indivíduo. Além disso, temos muita certeza de que um direito humano está em questão quando nos sentimos horrorizados pela sua violação" (HUNT, 2009, p.15). As resistências aos afetos entre as pessoas do mesmo sexo ou às diversas orientações sexuais, as críticas às identidades de gênero, aliadas ao preconceito e ao não reconhecimento das alteridades, retardou uma ordem social que adote igualdades nas particularidades.

As novas uniões e formações de entidades familiares adquirem direitos típicos e próprios, não sendo mais encaradas como sociedades civis ou como simples arranjos pessoais. A importância que se dá na realização do afeto entre as pessoas nas mais

\footnotetext{
${ }^{13}$ Ação Direta de Inconstitucionalidade (ADI) 4277 e a Arguição de Descumprimento de Preceito Fundamental (ADPF) 132, STF, maio de 2011. O casamento direito entre pessoas do mesmo sexo foi regulamentado através da Resolução nº 175/2013, CNJ.
} 
diversas manifestações de conjugalidade e de parentalidade irá romper com as estruturas até então consolidadas.

5. O trabalho extradomicílio da mulher: resistências e necessidades

Nesse ambiente de mutação familiar, a Constituição Federal de 1988 foi marco importante nos processos de reconhecimentos e especialmente na realização das igualdades entre homens e mulheres e entre cônjuges e companheiros. Ao inserir expressamente em duas diferentes oportunidades o comando das igualdades ${ }^{14}$, a norma orienta que ela deve se dar para além da forma, atingindo materialmente as relações familiares não apenas para mitigar, mas para extirpar os casos de iniquidade no âmbito específico das realizações e direitos familiares.

No plano das relações de trabalho e de direitos sociais, há importante alteração constitucional em 1988, com a licença maternidade sendo ampliada de 90 (noventa) para 120 (cento e vinte) dias. À época dos debates, dentre as questões suscitadas e usadas como argumento para impedir a proteção desse direito dos filhos, estava o alto custo para o empregador em manter afastada a mulher por cento e vinte dias. $\mathrm{O}$ custo não se dá exatamente em razão do pagamento, que será suportado ou compensado no pagamento da Seguridade Social, mas em decorrência de se deixar por tanto tempo um substituto não necessariamente treinado para o cargo. Essa questão poderia implicar em redução e contratações de mulheres, em especial aquelas em idade fértil.

De outro lado, as pesquisas desenvolvidas pela psicanálise e pela medicina demonstravam a importância não apenas do aleitamento materno, mas dos cuidados parentais nos primeiros anos de vida infantil. A importância das funções materna e paterna na constituição psíquica e como refletem no desenvolvimento da criança, que depende do Outro para sobreviver, assim como do Pai para ser inserido na Cultura (FREUD, 1912) parece argumento suficiente a ensejar maior contato familiar, considerando o tempo e o envolvimento de pais continentes.

O paradoxo advindo da imperatividade de contato familiar para os filhos e a vontade e necessidade de permanecer no mercado de trabalho, o que ensejou o aumento de prazo para 120 (cento e vinte) dias, é relevante na participação da mulher no mercado

${ }^{14}$ Art. $5^{\circ}$ e art. 226 da Constituição Federal de 1988.

Rev. Brasileira de História do Direito | e-ISSN: 2526-009X| Goiânia| v. 5 | n. 1 | p. 1 - 20 | Jan/Jun. 2019 


\section{MÍDIA, (IN)FORMAÇÃO E DECISÕES JUDICIAIS: UMA COMPREENSÃO DA \\ HERMENÊUTICA NA SOCIEDADE ATUAL.}

de trabalho e cria novos paradoxos ou verdadeiros impedimentos. No caso das servidoras públicas, esse tempo pode ser ampliado para 180 (cento e oitenta) dias, permitindo um período maior com o bebê.

A parentalidade - e o que se propõe é que seja vista de forma conjunta - impõe responsabilidades e cuidados aos pais que por vezes são suportadas tão somente pela mulher. As dificuldades com a educação e sustento dos filhos e a falta de aparelhamento que apoie a educação, como creches e escolas próximas aos trabalhos e residências, deslocamentos longos e cansativos, dificultam as atividades profissionais.

O Brasil tem como projeto que ao menos $50 \%$ (cinquenta por cento) das crianças de 0 a 3 anos frequentem creches até o final do $\mathrm{PNE}^{15}$ em 2024. As Regiões Sul e Sudeste, que possuem as maiores percentagens, contam com 40,0\% e 39,2\% das crianças em inclusão ${ }^{16}$. Esses números impactam na inserção ou na continuidade de mulheres no mercado de trabalho. A criação e redes de parentesco e de vizinhanças para a ajuda coletiva de determinado grupo pode ser determinante para a continuidade das atividades remuneradas.

O trabalho extradomicilio não advém apenas da vontade de desenvolver atividades extramuros, mas também de autonomia e de autoestima. Igualmente decorre da necessidade econômica de ingresso das mulheres no mercado para equilibrar ou garantir a economia doméstica, servindo a remuneração para o sustento pessoal ou da família.

As mulheres pobres precisam - e sempre precisaram - de trabalho remunerado. As mulheres ricas estudam mais e querem compartilhar os novos conhecimentos. Novos produtos são desenvolvidos e colocados em mercado, aumentando o desejo de consumo e a necessidade de renda (BRUSCHINI, 1994).

As crises econômicas enfrentadas no país interferem e devem ser consideradas como desencadeadoras do aumento do número de mulheres no mercado de trabalho. As famílias buscam soluções para atravessar o período e possivelmente as mais pobres colocarão mais mulheres em postos de trabalhos.

\footnotetext{
${ }^{15}$ Meta 1 do Plano Nacional de Educação - PNE, instituído pela Lei n. 13.005, de 25.06.2014.

${ }^{16}$ Pesquisa Nacional por Amostra de Domicílios Contínua - PNAD Contínua, 2017, disponível em https://agenciadenoticias.ibge.gov.br
} 
Em 2010, o IBGE ${ }^{17}$ apura que as mulheres eram minoria na população ocupada e maioria na população não economicamente ativa, estimado em 11,3 milhões. A maioria das mulheres ocupadas tinha entre 25 e 49 anos de idade, idade em que geralmente acumulam as atividades extramuros com as domésticas em seus lares ou no de terceiros, sendo essa a atividade mais desempenhada. Em relação à escolaridade, $61,2 \%$ das trabalhadoras tinham o ensino médio completo e dessa população, $19,6 \%$ com curso superior completo. Ainda assim, a participação dos homens permanece superior a das mulheres. Esses números, aliados ao baixo índice de trabalhadoras com carteiras assinadas, implica em menor taxa de recolhimento para a previdência social, impactando ao longo da atividade laboral com a ausência de direitos do trabalho e futuramente na aposentadoria, carregando o problema para a velhice, inclusive.

Os índices oficiais informam que as mulheres trabalham menos horas fora de seus domicílios, mas a soma das atividades intradomésticas e extradomiciliar implica em uma carga horária estendida em comparação com os homens. Da mesma forma, a renda das mulheres é inferior a dos homens. As discrepâncias podem advir da carga horária externa reduzida ou ainda da resistência em diversos ambientes de trabalho em igualar os salários de homens e mulheres.

O capitalismo parece criar uma nova alavanca nessas relações que podem ser percebidas de forma dúplice. Se de um lado impulsionam o trabalho e permitem a criação e ocupação de novos postos para as mulheres, o que também implica em mais oportunidades de estudos e de conhecimentos, de outro lado podem redesenhar os papeis familiares. As mulheres passarão mais tempo fora de casa do que anteriormente, sendo necessária uma nova dinâmica familiar. Se até então o modelo brasileiro imputava às mulheres todos os cuidados com os filhos e as atividades da casa, para conciliar as atividades novas organizações serão propostas.

Algumas famílias aproveitam a oportunidade para reorganizar as suas conjugalidades e o desvelo da paternidade. Nesses casos, será possível encontrar homens que atuarão nas atividades domésticas e de cuidados com os filhos, abrindo caminhos para a paternidade responsável. Em outras famílias, especialmente as mais pobres, haverá resistências não apenas ao trabalho, mas ao exercício de atividades

\footnotetext{
${ }^{17}$ IBGE, Mulher no mercado de trabalho : perguntas e respostas, 2010. Disponivel em https://ww2.ibge.gov.br/home/estatistica/indicadores/trabalhoerendimento/pme_nova/Mulher_Mercado_T rabalho_Perg_Resp.pdf Acesso em 04 abr. 2019.
} 


\section{MÍDIA, (IN)FORMAÇÃO E DECISÕES JUDICIAIS: UMA COMPREENSÃO DA \\ HERMENÊUTICA NA SOCIEDADE ATUAL.}

consideradas tipicamente femininas - os cuidados da casa - impondo jornadas exaustivas e não reconhecidas socialmente. Algumas atividades são associadas à condição feminina e atribuídas às mulheres, como os empregos domésticos, aonde $92,3 \%$ das trabalhadoras são mulheres ${ }^{18}$ que trabalham nas casas de outras pessoas, e o magistério, enfermagem e serviço social.

As diferenças salariais permanecem e são significativas. No ano de 2018 ainda é possível encontrar discrepâncias de até $77,5 \%$ do rendimento pago aos homens no Brasil, contra $77,2 \%$ em $2016^{19}$. As diferenças na educação formal também é um fator determinante, mas ainda assim, mesmo em condições semelhantes de escolaridade, ainda assim o homem percebe salários superiores. O fenômeno é comum na América Latina para todas as faixas etárias e de educação ${ }^{20}$. A questão permanece na irresignação em atribuir o real sentido para a igualdade de gêneros. Cristalizadas para além do plano político, com repercussões significativas no ambiente familiar, são reveladas nos relatos de assédio pelas diferenças e praticadas em face da condição feminina.

O trabalho doméstico, invisível em sem remuneração, permanece sob a responsabilidade das mulheres. Não é um atributo, mas atribuído e para que haja liberdade, a repartição e compartilhamento das responsabilidades familiares não hierarquizadas oportunizariam as igualdades sociais.

\section{CONCLUSÕES}

Ao investigar o comportamento social e a resposta apresentada pela normativa, busca-se também identificar quão imbricados os fenômenos podem ser considerados. Há movimentos mais ou menos resistentes e conhecer como eles podem retardar ou precipitar as mudanças acerca das diferenças nos direitos ao trabalho das mulheres em comparação com os homens revelam quão expressivas e persistentes elas são.

Nas relações de trabalho, o abuso não se esconde. Ele é declarado sob as mais diversas facetas e diferenças. Elas não são apenas salarias ${ }^{21}$, mesmo sendo significativas, mas também em discursos pseudo-igualitários verificados através da interrupção da fala das mulheres, da designação de atribuições secundárias ou que não

\footnotetext{
${ }^{18}$ IBGE, PNAD cont[inua, 2017, Disponível em https://agenciadenoticias.ibge.gov.br

${ }^{19}$ IBGE https://agenciadenoticias.ibge.gov.br

${ }^{20}$ Pesquisa do BID em http://www.observatoriodegenero.gov.br

${ }^{21}$ IBGE https://agenciadenoticias.ibge.gov.br
} 
levem o nome da mulher como titular, ou ainda na realização de atividades supostamente designadas como de acolhimento, como se houvesse uma afetividade ou fragilidade inerentes ao desempenho da função.

Para superar o modelo patriarcal ainda consolidado na América Latina e atingir um sistema de liberdade decisória, parecem necessárias mudanças também nos paradigmas e na cultura jurídica. A permanência nem tão velada em sistema colonial e a repetição dos papeis até então consolidados nas famílias justifica ampliar o debate para os espaços doméstico e de trabalho contemporâneos.

Foi identificado que os direitos civis tiveram maior resistência, alterações e importância nas relações de trabalho da mulher no que se refere especificamente ás regras típicas de direito do trabalho da mulher. A oposição é social, que mantém conceitos conservadores atravancando as inserções no mercado e o exercício das igualdades.

Os avanços são lentos e por vezes permeados por retrocessos. Não há exatamente uma linha contínua na organização das famílias com a aceleração do processo pelos direitos civis das mulheres. A redução do poder político do homem no ambiente doméstico implica em outros arranjos interessantes, mas nem sempre aceitos. Os eixos das mudanças permanecem na inclusão social, possivelmente ampliando a representação feminina no legislativo, e na proteção ao trabalho, a luta pela liberdade sexual e os direitos materno-filiais. O combate à tutela patriarcal e de titularidade do corpo constituem parte significativa da pauta da igualdade de gêneros em debate para a continuidade da pesquisa, verificando a interação dos processos históricos com a normativa, o país real e as demandas sociais.

\section{REFERÊNCIAS BIBLIOGRÁFICAS}

ANDRADE, Tania. Mulheres no mercado de trabalho: onde nasce a desigualdade? Consultoria legislativa, Direito do Trabalho e processo do Trabalho. Brasília: Câmara dos Deputados, 2016. Disponível em http://www2.camara.leg.br/a-camara/documentose-pesquisa/estudos-e-notas-tecnicas/areas-da-conle/tema7/2016_12416_mulheres-nomercado-de-trabalho_tania-andrade

ARAÚJO, R. Mary Wollstonecraft e Nísia Floresta: diálogos feministas. Revista Água Viva, v. 1, n. 1, 14 abr. 2011. Disponível em http://periodicos.unb.br/index.php/aguaviva/article/view/10765 Acesso em 03 abr. 2019 ARIÈS, P. Por uma história da vida privada. In: ARIÈS, P. e DUBY, G. História da Vida Privada, vol. 3. São Paulo: Companhia das Letras, 2009. 
Barros, R. P.; Corseuil, C. H.; Santos, D. D. dos; Firpo, S. P. Inserção no mercado de trabalho: diferenças por sexo e conseqüências sobre o bem-estar. IPEA, 2001. Disponível em Barros, R. P.; Corseuil, C. H.; Santos, D. D. dos; Firpo, S. P. Inserção no mercado de trabalho: diferenças por sexo e conseqüências sobre o bem-estar. IPEA, 2001. Mimeografado. Acesso em 03 abr. 2019.

BRASIL. Lei ${ }^{\circ} 3.071$, de $1^{\circ}$ de janeiro de 1916. Institui o Código Civil. Diário Oficial da República Federativa do Brasil, Diário Oficial da União. Seção 1. 05/01/1916. p. 133.

Decreto-Lei n. 5.452, de $1^{\circ}$ de maio de 1943. Consolidação das Leis do Trabalho - CLT.

. Lei $\mathrm{n}^{\circ} 4.121$, de 27 de agosto de 1962. Dispõe sôbre a situação jurídica da mulher casada. Diário Oficial da República Federativa do Brasil, Diário Oficial da União. 03/09/1962.

. Lei n. 6.515, de 26 de dezembro de 1977. Regula os casos de dissolução da sociedade conjugal e do casamento, seus efeitos e respectivos processos, e dá outras providências. Diário Oficial [da] República Federativa do Brasil, Brasília, DF, ano 115, n. 248, 27 dez. 1977. Seção 1, p. 17953-17957. Retificada no Diário, 11 abr. 1978, Seção 1, p. 5073.

Constituição (1988). Emenda Constitucional n. 66, de 13 de julho de 2010. Dá nova redação ao $\S 60$ do art. 226 da Constituição Federal, que dispõe sobre a dissolubilidade do casamento civil pelo divórcio, suprimindo o requisito de prévia separação judicial por mais de 1 (um) ano ou de comprovada separação de fato por mais de 2 (dois) anos. Diário Oficial da União, Brasília, DF, ano 147, n. 133, 14 jul. 2010. Seção 1, p. 1-2.

. Lei $\mathrm{n}^{\circ} 8.971$, de 29 de dezembro de 1994. Regula o direito dos companheiros a alimentos e à sucessão. Diário Oficial da República Federativa do Brasil, Diário Oficial da União. 30/12/1994.

Lei $\mathbf{n}^{\circ}$ 9.278, de 10 de maio de 1996. Regula o $\S 3^{\circ}$ do art. 226 da Constituição Federal. Diário Oficial da República Federativa do Brasil, Diário Oficial da União. 13/05/1996.

Lei $\mathrm{n}^{\circ} 10.406$, de 11 de janeiro de 2002. Institui o Código Civil. Diário Oficial

da República Federativa do Brasil, Diário Oficial da União. - Seção 1 - 11/1/2002, Página 1.

BRUSCHINI, Cristina. O trabalho da mulher brasileira nas décadas recentes. Revista Estudos femininos. Rio de Janeiro: Fundação Universitária José Bonifácio, 1994.

CASTRO, Ana Elisa Ferreira de e YAMAMOTO, Oswaldo H.. A Psicologia como profissão feminina: apontamentos para estudo. Estudos de Psicologia Comunicações breves 1998, 3(1), 147-158.

CONSELHO NACIONAL DE JUSTIÇA (Brasil). Resolução n. 175, de 14 de maio de 2013. Dispõe sobre a habilitação, celebração de casamento civil, ou de conversão de união estável em casamento, entre pessoas de mesmo sexo. Diário do Senado Federal, Brasília, DF, ano 58, n. 71, 17 maio 2013.

COSTA, Jurandyr. Ordem Médica e Norma Familiar. São Paulo: Graal Editora, 1979. FREUD, Sigmund. (1913 [1912-13]). Totem e Tabu. In: Edição Standard Brasileira das Obras Psicológicas Completas de Sigmund Freud (ESB). Rio de Janeiro: Editora Imago, 1974, v. 14.

GARCIA, Carla Cristina. Breve História do feminismo. São Paulo: Claridade; $4^{\text {a }}$ Edição, 2011. 
HUNT, L. A invenção dos Direitos Humanos: Uma história. São Paulo: Companhia das Letras, 2009.

IBGE. Estudo de Estatísticas de Gênero. 2018. Disponível em https://www.ibge.gov.br

Pesquisa Nacional por Amostra de Domicílios Contínua (PNAD Contínua), Disponível em https://www.ibge.gov.br

_. Estudo Retrato das Desigualdades de Gênero e Raça. Disponível em https://www.ibge.gov.br

Mulher no mercado de trabalho: perguntas e respostas, 2010. Disponivel em https://ww2.ibge.gov.br/home/estatistica/indicadores/trabalhoerendimento/pme_nova/Mulher_ Mercado_Trabalho_Perg_Resp.pdf

KARAWEJCZYK . Mônica. As filhas de Eva querem votar: dos primórdios da questão à conquista do sufrágio feminino no Brasil.(c.1850-1932). Disponível em http://www.lume.ufrgs.br/handle/10183/72742

LEVI- STRAUSS, Claude. 1956. A família. In Homem, cultura e sociedade. Rio de Janeiro: Editora Fundo de Cultura

LOPES, Cristiane Maria Sbalqueiro. Direito do trabalho da mulher: da proteção à promoção. cadernos pagu (26), janeiro-junho de 2006: pp.405-430.

MIRANDA, Cynthia Mara. Os movimentos feministas e a construção de espaços institucionais para a garantia dos direitos das mulheres no Brasil. Disponível em http://www.ufrgs.br/nucleomulher/arquivos/os\%20movimentos $\% 20$ feminismtas_cyntia. pdf

OIT. Relatório global sobre os salários 2016/17. Disponível em http://www.ilo.org/wcmsp5/groups/public/---dgreports/---dcomm/---

publ/documents/publication/wcms_537997.pdf

PEREIRA, Hildete Pereira de Melo e SCHUMAHER, Schuma. A segunda onda feminista no Brasil. $\quad$ Disponível em http://www.mulher500.org.br/uploads/conteudo/3_A-segunda-onda-feminista-no-

Brasil.pdf

Observatório Brasil da Igualdade de Gênero. Disponível em http://www.observatoriodegenero.gov.br

PERROT, Michelle. Funções da família In: ARIÈS, P. e DUBY, G. História da Vida privada. Vol. 4. Organização Michelle Perrot. São Paulo: Companhia das Letras. 2012. 